\title{
A RETROSPECTIVE COMPARATIVE STUDY OF PREPERITONEAL VS ONLAY MESH REPAIR IN CASES OF VENTRAL HERNIA AT TERTIARY CARE INSTITUTE.
}

\section{General Surgery}

Dr. Manubhai V. Pipalia

Professor \& Head Of The Department, Department Of General Surgery, GCS Medical Dr. Ronak Rajubhai Chavada* College, Hospital And Research Centre.

Resident Doctor, Department Of General Surgery, GCS Medical College, Hospital And Research Centre. *Correspondign Author

\begin{abstract}
Background: A ventral hernia is an abnormal protrusion of intra abdominal or preperitoneal content through the anterior abdominal wall fascia and muscle defect. Hernioplasty with prosthetic mesh is surgical treatment modality for all types of ventral hernia.There are various anatomic planes where mesh can be put. This study was planned to compare preperitoneal repair and onlay mesh repair in terms regarding their outcome. Methods: This is a retrospective study with total number of 112 cases of ventral hernia with prosthetic meshplasty was done. In all cases clinical history, preoperative examination findings, intraoperative and post operative findings were noted. All data was categorised according to where mesh was put intra-operatively in anatomical plane of preperitoneal or onlay. Statistical analysis of all data was done and outcome was measured. Results: Mean operative time was less in onlay hernioplasty than preperitoneal hernioplasty but over all complications were high in onlay hernioplasty.Preperitoneal hernioplasty method had lowest complications rate.
\end{abstract}

Conclusions: Preperitoneal hernioplasty is better choice than onlay hernioplasty.

AIM: To assess the better method from onlay meshplasty and preperitoneal meshplasty in cases of ventral hernia.

OBJECTIVE: To compare the both methods on the bases of operative time ,speed of postoperative period recovery, and postoperative complications.

\section{KEYWORDS}

Ventral Hernia, Preperitoneal, Onlay

\section{INTRODUCTION:}

Ventral hernia refers to hernias of the anterior abdominal wall. Inguinal and femoral hernias are not included even though they are ventral. Lumbar hernia is included despite being dorsolateral. ${ }^{1}$ A ventral hernia is defined by a protrusion through the anterior abdominal wall fascia. This may be present at birth or acquired from weakening or disruption of the overlying fascia, or from failed healing of a surgical incision. These defects can be categorized as spontaneous or acquired.

Nonincisional hernias are named based on their location on the abdominal wall. Epigastric hernias occur from the xiphoid process to the umbilicus, umbilical hernias occur at the umbilicus, and hypogastric hernias are rare spontaneous hernias that occur below the umbilicus in the midline. Acquired hernias typically occur after surgical incisions and are therefore termed incisional hernias.

Hernias may present as asymptomatic bulges that increase with Valsalva maneuvers, or with significant discomfort. Hernias may reduce spontaneously or with manual pressure. If a hernia is incarcerated, it cannot be reduced and generally requires surgical correction. If intestine is incarcerated in the hernia defect, bowel obstruction may ensue, which represents a surgical emergency. A hernia is considered strangulated if blood supply to its contents is compromised. Localized ischemia may lead to infarction and eventual perforation if left untreated. These hernias are usually small but may be associated with multiple defects. They result from multiple factors, including muscle weakness, congenitally weakened epigastric fascia, or increases in intra-abdominal pressure.

Surgeon has various options for placing the mesh.

The onlay technique involves primary closure of the fascia defect and placement of a mesh over the anterior fascia. The major advantage of this approach is that the mesh is placed outside the abdominal cavity, avoiding direct interaction with the abdominal viscera. However, disadvantages include the large subcutaneous dissection, the increased likelihood of seroma formation, the superficial location of the mesh (which places it in jeopardy of contamination if the incision becomes infected), and the repair is usually under tension. ${ }^{2,5}$

The preperitoneal technique involves placing the prosthetic material below the fascial components. The mesh can be placed intraperitoneally, preperitoneally, or in the retrorectus (retromuscular) space. It is highly desirable to have the mesh placed beneath the fascia.
With a wide overlap of mesh and fascia, the natural forces of the abdominal cavity act to hold the mesh in place and prevent migration. ${ }^{2,}$

\section{MATERIALSAND METHODS:}

Total 112 cases of ventral hernia operated from June 2017 to June 2018 admitted in GCS Medical College and Research Centre, were retrospectively evaluated according to the inclusion exclusion criteria. Two groups were made according to mesh placement in anatomical plane onlay[group A] or preperitoneal[group B]. There were 50 cases operated in wich onlay repair were done.There were 72 cases in which preperitoneal repair were done. Outpatient clinical notes, discharge summary, operative notes, and laboratory data were reviewed.

\section{Inclusion criteria for study:}

1. All patients having the ventral hernia i.e. umbilical, paraumbilical, spigelian, incisinal hernias

2. Age $>18 \mathrm{yr}$

3. Hernia defect size $>2 \mathrm{~cm}$

\section{Exclusion criteria for study:}

1. Age $<18$ years

2. Acute incarcerated hernia

3. Infected hernia

4. Patient requiring the other surgical procedure apart from hernia repair in the same setting

5. Patient not fit for the surgery or anesthesia.

\section{RESULTS:}

Out of 112 patients, $77[69 \%]$ were female and $35[31 \%]$ were male, with a female to male ratio of 1.7 to 1 . Ages ranged from 18 to 75 years. 40 patients had incisional hernia, 11 patients had epigastric hernia, 60 patients had umbilical hernia and 1 had infraumbilical hernia. [Figure 1 and 2]

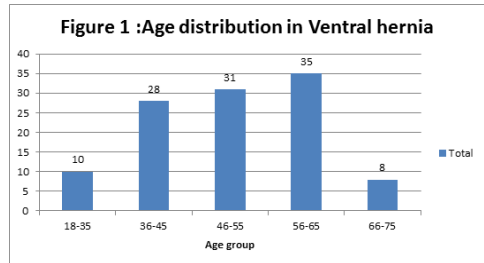


Figure 2: Type of Ventral hernia and Sex

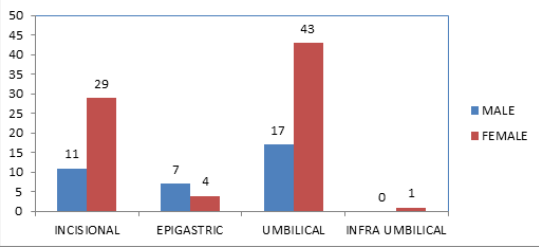

Regarding to the duration of surgery in patients treated with onlay mesh repair (Group A) ranged from 46-67 minutes (56.34 mean time). While in patients treated with preperitoneal mesh repair (Group B) it ranged from 79-100 minutes (89.45 minutes mean time) [Figure 3]

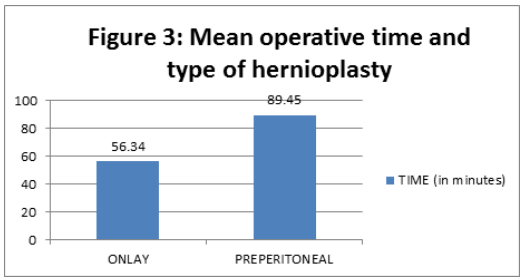

There were complications like seroma, superficial surgical site infection, deep surgical site infection and recurrence rate (was decided on 1 year follow up period). The data was calculated and compared with other groups. [Figure 4]

Figure 4: Comparison of complications in type of hernioplasty

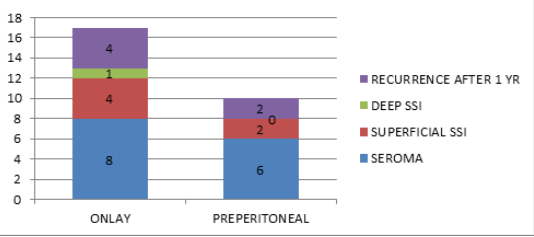

\section{DISCUSSION}

Ventral hernia either De novo or recurrent is a common surgical problem and refers to fascial defect of the anterolateral parietal abdominal wall fascia and muscles, through which intermittent or continuous protrusion of intra-abdominal or preperitoneal contents occurs. ${ }^{6}$

Regarding to the duration of surgery in patients treated with onlay mesh repair (Group A) ranged from 46-67 minutes (56.34 mean time) which is shorter than the Alsoudany SM et al. ${ }^{7}$ 75-90 minutes $(83.41+10.24)$ and longer than that reported by Godara et al. ${ }^{8}$ of which the duration of surgery ranged from $30-90$ minutes (49.35 \pm 8.29). [Table 1]

Table 1: Comparison of mean operative time in onlay hernnioplasty with other type of studies.

\begin{tabular}{|l|l|l|}
\hline $\begin{array}{l}\text { TYPE OF HERNIA } \\
\text { REPAIR }\end{array}$ & STUDY & $\begin{array}{l}\text { MEAN OERATIVE } \\
\text { TIME [minutes] }\end{array}$ \\
\hline Onlay & Alsoudany SM et $\mathrm{al}^{7}$ & 83.41 \\
\hline Onlay & Godara et $\mathrm{al}^{8}$ & 49.35 \\
\hline Onlay & Present study & 56.34 \\
\hline
\end{tabular}

We recorded the duration of surgery in patients treated with preperitoneal mesh repair (Group B) that ranged from 79-100 minutes (89.45 minutes mean time)which is less than reported by Rajsiddharth $\mathrm{B}$ et al. ${ }^{9}$ Who reported mean time of 60.15 minutes, this may be attributable to epidemiological variations of patients. [Table 2]

Table 2: Comparison of mean operative time in preperitoneal hernnioplasty with other type of studies.

\begin{tabular}{|l|l|l|}
\hline $\begin{array}{l}\text { TYPE OF HERNIA } \\
\text { REPAIR }\end{array}$ & STUDY & $\begin{array}{l}\text { MEAN OERATIVE } \\
\text { TIME [minutes] }\end{array}$ \\
\hline Preperitoneal & Rajsiddharth B et al & 60.15 \\
\hline Preperitoneal & Present study & 89.45 \\
\hline
\end{tabular}

Seroma is one of the most common complications following open technique and is particularly likely to occur when large skin flaps are developed during the surgical procedure. Although small seromas frequently resolve within 6 to 8 weeks without squeal, a large symptomatic or persistent seroma occasionally requires multiple aspirations or again have to place the drain if multiple aspirations need to be avoided, as there is increased risk for secondary infection with multiple aspirations attempts.

In this study regarding Seroma formation after drain removal in patients treated with onlay mesh repair (Group A), seroma occurred in 8 patients $(16 \%)$ which is slightly on higher side than reported by Alsoudany SM et al. ${ }^{7}$ of which $15 \%$ of cases of onlay repair developed seroma, similar to that reported by Godara et al. ${ }^{8}$ which was $15 \%$ as in same group, but higher than that reported by Kohler et al. ${ }^{11}$ of which $12.5 \%$ of cases developed wound seroma and higher than the study done by Bauer et al. ${ }^{10}$ that showed a $5 \%$ incidence of seroma. [Table 3]

Table 3: Comparison of seroma in onlay hernioplasty with other type of studies.

\begin{tabular}{|l|l|l|}
\hline $\begin{array}{l}\text { HERNIA } \\
\text { REPAIR }\end{array}$ & STUDY & $\begin{array}{l}\text { RATE OF SEROMA } \\
\text { FORMATION }\end{array}$ \\
\hline Onlay & ${\text { Alsoudany SM et } \mathrm{al}^{7}}^{7}$ & $15 \%$ \\
\hline Onlay & ${\text { Godara et } \mathrm{al}^{8}}^{{ }^{1}}$ & $15 \%$ \\
\hline Onlay & ${\text { Bauer et } \mathrm{al}^{10}}^{11}$ & $5 \%$ \\
\hline Onlay & Kohler et al. $^{11}$ & $12.5 \%$ \\
\hline Onlay & Present study & $16 \%$ \\
\hline
\end{tabular}

Seroma formation after drain removal in patients treated with preperitoneal mesh repair (Group B), occur in 6 of the cases of this group (8.3\%) which is lower than that reported by Rajsiddharth B et al ${ }^{9}$ in which seroma occurred in about $10 \%$ of cases and than that reported by Godara et al. ${ }^{8}$ in which seroma occurred in about $22.5 \%$ of cases. Which may be attributable to the relatively small number of cases in our study, more number of cases may be required for the same to be more conclusive. [Table 4]

Table 4: Comparison of seroma in preperitoneal hernioplasty with other type of studies.

\begin{tabular}{|l|l|l|}
\hline $\begin{array}{l}\text { TYPE OF HERNIA } \\
\text { REPAIR }\end{array}$ & STUDY & $\begin{array}{l}\text { RATE OF SEROMA } \\
\text { FORMATION }\end{array}$ \\
\hline Preperitoneal & ${\text { Rajsiddharth B et } \mathrm{al}^{9}}^{9}$ & $10 \%$ \\
\hline Preperitoneal & ${\text { Godara et } \mathrm{al}^{8}}^{8}$ & $22.5 \%$ \\
\hline Preperitoneal & Present study & $8.3 \%$ \\
\hline
\end{tabular}

Obese patients, wide areas of dissection, and the presence of devitalized tissues are conditions favouring infection which is a real threat to the successful repair, when suppuration occurs in the wound, drainage and proper antibiotics are essential. ${ }^{1 .}$

Postoperative wound infection in patients treated with onlay mesh repair (Group A), 5 patients $(10 \%)$ developed wound infection ( 1 of them was a major wound infection i.e. deep surgical site infection, necessitated mesh removal and the others showed good response to conservative treatment of opening of wound and regular dressing), which is lower than that observed by Alsoudany SM et $\mathrm{al}^{7}$ of which $15 \%$ of cases developed the surgical site infection and reported by Godara et al. ${ }^{8}$ of which $15 \%$ of cases developed wound infection. It was significantly lower than that reported by Bauer et al. ${ }^{10}$ who reported that wound infection occurred in $23 \%$, but almost similar to that reported by Kohler et al. ${ }^{11}$ of which wound infection occurred in $9.3 \%$ of cases. [Table 5]

Table 5: Comparison of post operative wound infection in onlay hernioplasty with other type of studies.

\begin{tabular}{|l|l|l|}
\hline $\begin{array}{l}\text { TYPE OF } \\
\text { HERNIA REPAIR }\end{array}$ & STUDY & $\begin{array}{l}\text { RATE OF POST OPERATIVE } \\
\text { WOUND INFECTION }\end{array}$ \\
\hline Onlay & $\begin{array}{l}\text { Alsoudany SM } \\
\text { et al }^{7}\end{array}$ & $15 \%$ \\
\hline Onlay & Godara et al. $^{8}$ & $15 \%$ \\
\hline Onlay & Bauer et al $^{10}$ & $23 \%$ \\
\hline Onlay & Kohler et al. $^{11}$ & $2.5 \%$ \\
\hline Onlay & Present study & $10 \%$ \\
\hline
\end{tabular}

Our study shows that postoperative wound infection in patients treated with preperitoneal mesh repair (Group B), 2 patients $(2.8 \%$ ) developed superficial surgical site infection and no case of deep surgical site infection was noted. This rate is much lower than that observed by Rajsiddharth B et al. ${ }^{9}$ which is $6.66 \%$ and that reported by Yaghoobi et al. ${ }^{12}$ who reported that infection rate occurred in $11.6 \%$ cases and that reported by Godara et al. ${ }^{8}$ of which $22.5 \%$ cases developed wound infection but slightly lower than that reported by Kohler et al. ${ }^{11}$ of which wound infection occurred in $9.3 \%$ cases. [Table 6] 
Table 6: Comparison of post operative wound infection in preperitoneal hernioplasty with other type of studies.

\begin{tabular}{|l|l|l|}
\hline $\begin{array}{l}\text { TYPE OF HERNIA } \\
\text { REPAIR }\end{array}$ & $\begin{array}{l}\text { SATE OF POST } \\
\text { OPERATIVE WOUND } \\
\text { INFECTION }\end{array}$ \\
\hline Preperitoneal & Rajsiddharth B et al. $^{9}$ & $6.6 \%$ \\
\hline Preperitoneal & Yaghoobi et al. $^{12}$ & $11.6 \%$ \\
\hline Preperitoneal & Godara et al. $^{8}$ & $22.5 \%$ \\
\hline Preperitoneal & Kohler et al. & $9.3 \%$ \\
\hline Preperitoneal & Present study & $2.8 \%$ \\
\hline
\end{tabular}

Hernia recurrence was observed in patients treated with onlay mesh repair (Group A), 4 patients ( $8 \%$ ) developed hernia recurrence within 1 year post-operative period, which is slightly lower than that reported by Bauer et $\mathrm{al}^{10}$ who reported that recurrence rate is about $10 \%$, and this may be attributable to the shorter period of follow up in our study. But the rate is higher than that reported by Alsoudany SM et $\mathrm{al}^{7}$ who reported $5 \%$ recurrence rate over the period of 1 year, Kohler et al. ${ }^{11}$ who reported that recurrence rate of about $3.1 \%$ and than that reported by Godara et al. ${ }^{8}$ with no recurrence after a follow-up of minimum 24 months. [Table 7]

Table 7: Comparison of recurrence in onlay hernioplasty with other type of studies.

\begin{tabular}{|l|l|l|}
\hline $\begin{array}{l}\text { TYPE OF HERNIA } \\
\text { REPAIR }\end{array}$ & STUDY & $\begin{array}{l}\text { RECURRENCE } \\
\text { RATE }\end{array}$ \\
\hline Onlay & Alsoudany SM et al & $5 \%$ \\
\hline Onlay & Bauer et al $^{10}$ & $10 \%$ \\
\hline Onlay & ${\text { Kohler et } a .^{11}}{ }^{8}$ & $3.1 \%$ \\
\hline Onlay & Godara et al. & $0 \%$ \\
\hline Onlay & Present study & $8 \%$ \\
\hline
\end{tabular}

In this study regarding hernia recurrence in patients treated with preperitoneal mesh repair (Group B) 2 cases (2.8\%) developed hernia recurrence within 1 year post-operative period. Though in study by Rajsiddharth B et al. ${ }^{9}$ There were no cases of recurrence over the period of 1 year. [Table 8]

Table 8: Comparison of recurrence in preperitoneal hernioplasty with other type of studies.

\begin{tabular}{|l|l|l|}
\hline $\begin{array}{l}\text { TYPE OF HERNIA } \\
\text { REPAIR }\end{array}$ & STUDY & $\begin{array}{l}\text { RECURRENCE } \\
\text { RATE }\end{array}$ \\
\hline Preperitoneal & Rajsiddharth B et al. $^{9}$ & $0 \%$ \\
\hline Preperitoneal & Present study & $2.8 \%$ \\
\hline
\end{tabular}

\section{CONCLUSION}

Ventral hernias are very common entity in general surgery practice. The exact knowledge of various types of repairs and their advantages and disadvantages are crucial for successful repair of the hernia. As our study has concluded that preperitoneal repair is better than the onlay type of repair. The larger and more diverse population may require to give the clear mandate to one procedure.

\section{DECLARATIONS}

Funding: None,

\section{Conflict of interest: None.}

\section{REFERENCES}

1. Bruce Tulloh \& Stephen J. Nixon.Abdominal wall, hernia and umbilicus.In: Williams NS, O'connell PR, Mccaskie AW eds. Baily \& love's short practice of surgery.27thed. Boca raton FL:CRC press;2018:1036-42.

2. Mark A. Malangoni, Michael J. Rosen. Hernias. In:Townsend CM, Beauchamp RD, Evers BM, Mattox KL, eds. Sabiston Textbook of Surgery The biological basis of modern surgical practice.20th ed.Philadelphia,PA:Elsevier;2017:1130-37.

3. Scott Kizy, Sayeed Ikramuddin. Abdominal Wall, Omentum, Mesentery, and Retroperitoneum. In:Brunicardi FC, Anderson DK, Billiar TR, Dunn DL, Hunter JG, Kao LS et al eds. Schwartz's principal of surgery. 11thed. New York, NY: McGraw-Hill; 2019:1554.

4. Stephen R.T. Evans and Parag Bhanot.Ventral Abdominal Hernia: Open and Minimally Invasive and Component Separation Release.In:Fischer JE,Ellison EC, Upchurch jr. GR, Galandiuk S, Gould JC, Klimberg V et al eds. Fischers'mastery of Surgery.7th ed. Philadelphia,PA:Walters kluwer;2019:558-64.

5. Ahluwalia HS, Pim Burger J, Quinn TH. Anatomy of the anterior abdominal wall. Operative Tech. in General Surgery 2004; 6(3): 147-155.

6. Ahmed M, Niaz A, Hussain A, Saeeduddin A. Polypropylene Mesh Repair of incisional Hernia. JCPS.2003; 13(8):440-442.

7. Alsoudany SM, Khalil OA, Shebl AG. Comparative Study between "Onlay" Versus "Retrorectus" Hernioplasty in Management of Uncomplicated Venteral Hernias.EJHM 2018;73(4):6423-30.

8. Godara R, Garg P, Raj H, Singla SL. Comparative Evaluation Of "Sublay" Versus "Onlay" Meshplasty In Ventral Hernias. The Internet Journal of Surgery 2006;DOI: $10.5580 / \mathrm{ad} 9$
9. Rajsiddharth B, Venkanna M, Kumar GA, Patlolla SR, Sriramoju S, Reddy BS Comparative Study of Onlay and Pre-Peritoneal Mesh Repair in the Management of Ventral Hernias. Int I SciStud 2015;3(7): 121-128.

10. Bauer JJ, Harris MT, Kreel I, Gelerent IM. Twelve years experience with polypropylene in repair of abdominal wall defect. Mt. Sinai. J. Med 2010;66(1): 20-5

11. Kohler L, Sauerland S, Meyer A, Saad S, Schüller BK, Knaebel HP, Seiler CM, 2005 Mesh implantation in onlay or sublay technique for closure of median ventral hernias: first results of a randomized clinical trial. Poster presented at the Congress of the German Surgical Association. https://convention.visitberlin.de/.../congresscalendar/135rdcongress-of-german-societ.

12. Yaghoobi NA, Farshi JS, Amoli HA, Salimi J, Mamarabadi M. Outcomes of the Rives-Stoppa technique in incisional hernia repair: ten years of experience. Hernia 2006; 11(1):25-9.

13. Robert MZ. Complications of general surgery Surg. Clin. N. Am2002;71[6]:1359-1361. 